\title{
Organizational Practices That Foster Knowledge Sharing: Validation across Distinct National Cultures
}

\author{
Sherry D. Ryan, John C. Windsor, Bashorat lbragimova, \\ and Victor R. Prybutok \\ University of North Texas, Denton, TX, USA
}

sherry.ryan@unt.edu; john.windsor@unt.edu;

bashorat.ibragimova@yahoo.com; victor.prybutok@unt.edu

\begin{abstract}
There is lack of empirical, broad-based research in the area of comparative, cross-cultural studies that focus on knowledge sharing. Using the knowledge-based view (KBV) as the theoretical foundation, the study investigates how organizational practices in two distinct national cultures support knowledge sharing activities and the associated supporting organizational practices that are widely transferable. We propose and empirically test a model that examines the relationships among strategic, decision and technology practices and organizational knowledge sharing in two distinct national cultures (US and Japan). The results of the study suggest that despite the existing cultural contrasts in these two countries there are some common organizational practices that positively impact an organization's knowledge-sharing environment. While these results support a model of core organizational practices that foster knowledge sharing and that are transferable across national cultures our findings also support the need for careful consideration of the type of practices applied across different cultures.
\end{abstract}

Keywords: knowledge sharing, cross-cultural studies, information technology, organizational factors, knowledge-based view of the firm

\section{Introduction}

The knowledge-based view (KBV) of the firm (Grant, 1996) asserts that coordination of knowledge at the organizational level is critical to realizing competitive advantages. While there has been debate in the literature regarding the definition of knowledge (e.g., Gackowski, 2004; Tuomi, 1999), in this paper we define knowledge as "the judgment of the significance of events and items which comes from a particular context and/or theory" (Tsoukas \& Vladimirou, 2001, p. 976). One way firms can realize coordination of knowledge is through the organizational practices by which they operate. Knowledge

Material published as part of this publication, either on-line or in print, is copyrighted by the Informing Science Institute. Permission to make digital or paper copy of part or all of these works for personal or classroom use is granted without fee provided that the copies are not made or distributed for profit or commercial advantage AND that copies 1) bear this notice in full and 2) give the full citation on the first page. It is permissible to abstract these works so long as credit is given. To copy in all other cases or to republish or to post on a server or to redistribute to lists requires specific permission and payment of a fee. Contact Publisher@InformingScience.org to request redistribution permission. sharing is a central aspect of the knowledge-based theory of the firm because it suggests that the primary reason for the existence of the firm is its superior ability to transfer and integrate multiple knowledge streams and to apply existing knowledge to tasks (Grant, 1996).

Organizations that have succeeded in using information technology (IT) to support knowledge sharing have found 
that technology alone is not sufficient to produce the desired results. Some suggest that organizational practices and policies are critical in knowledge sharing efforts (Brazelton \& Gorry, 2003). Organizational practices, strategies, and IT management are influenced not only by competitive or industry pressures but also by the national culture in which the organization exists (Leidner \& Kayworth, 2006). For example, differences exist between how North American and Asian respondents view information systems quality and how it is provided (Kettinger, Lee, \& Lee, 1995). Management practices that empowered employees resulted in different outcomes that were attributed to differences in national culture (Marchese, 2001). Yet, outcomes of managerial practices related to continuous improvement were similar in all the countries studied (U.S., Mexico, Poland, and India). Thus, we speculate that some of the organizational practices exercised in one country are not effective in another country due to differences in national culture while other organizational practices function equally well in different countries despite these cultural differences. In today's global economy, organizations must grapple with decisions about which managerial practices are reasonable to transfer and which require extensive modification for deployment across national borders.

A review of the literature reveals several identifiable deficiencies that have limited the understanding of knowledge sharing. First, little research has examined the role of national culture in key IT governance areas (Leidner \& Kayworth, 2006). Much of the research that exists was conducted in a single country, most often the United States. As a result, there is little understanding on how organizations from different national cultures perceive the relationships between organizational practices and knowledge sharing. Next, although some information systems researchers have explored the relationship between knowledge management in general and national culture, there is a paucity of studies published that have specifically addressed knowledge sharing in multiple national cultures and that have incorporated the IT artifact as a key component. Third, all but a handful of the empirical cross-cultural knowledge sharing studies use a case study methodology that provides rich descriptive data but does not demonstrate broad-based applicability. We use national surveys in the United States and Japan in our investigation and as a result report findings with greater generalizability. Fourth, while there are organizational-level knowledge sharing studies (Cho \& Lee, 2004; Malhotra, Gosain, \& Sawy, 2005), much of the knowledge sharing literature has focused on individual perceptions and characteristics rather than on organizational practices. Alony, Whymark, and Jones (2007) have called for additional research on organizational factors and knowledge sharing.

Given the factors mentioned above, this study makes a unique contribution by specifically addressing the following research question: "To what extent are core organizational practices that contribute to creating a knowledge sharing environment applicable in organizations that reside in distinctly different national cultures?"

To investigate this research question, we use the KBV of the firm to frame the relationship between organizational practices and knowledge sharing. We posit a model of three categories of organizational practices that affect knowledge sharing: business strategy, technology, and decision making, and then empirically test this model in the United States and Japan. These two countries were chosen because they represent nearly polar extremes in cultural values. According to Hofstede's (2001) dimensions of culture, Japan and the United States differ along four of the five dimensions: individualism, uncertainty avoidance, power distance, and long-term orientation.

While many empirical studies seek to identify differences based upon national culture, we seek to identify commonalities to produce a model of core practices that is transferable among countries with widely differing national cultures. This is consistent with the goal of science and the search for universal knowledge in which general theories are developed that are not limited to specific societal or national contexts. Cheng $(1994$, p. 162) describes two types of generally accepted cross-cultural research: (1) "findings that are invariant across different settings" and (2) findings 
that look for variances based upon the societal context. He argued, over a decade ago, that many studies that claimed cross-national applicability were conducted in a single nation and were not confirmed elsewhere. Heeding his warnings, today most studies are of the second type and identify and examine differences associated with national culture. We posit that studies of the first type should not be abandoned, but to test cross-cultural applicability they must be carried out in more than a single nation with attention to the aspects of national culture upon which the nations studied differ. Our intent is not to minimize the importance of recognizing that many cultural differences exist and that organizations should be extremely cautious when transferring managerial practices and policies from one culture to another. On the contrary, our work shows that a significant amount of thought should be given to what types of practices are applicable across different cultures and which are not.

A major contribution of this research is a generalizable KBV model of organizational practices in both western and eastern national cultures that is supported with empirical results from both the United States and Japan. A core set of practices is identified that is applicable in diverse national settings. Our model provides a baseline for exploring those practices that are beneficial in multiple cultures. Nevertheless, we realize that despite the general applicability of certain practices, small culturally bound differences still exist, and therefore, in a post-hoc analysis, we take a finegrained approach to understanding these differences. Our research helps fill the void in the literature, providing a cross-cultural, organizational-level model focusing on knowledge sharing. It also provides direction for practitioners to consider particular strategic, technology and decision making practices so that knowledge sharing can be enhanced in their organization.

Our study also contributes to the transdiscipline of the informing sciences because it sheds light on the organizational practices that shape the informing environment. In Cohen's recent update (2009) to his seminal work (1999) describing the Informing Science framework, he expands the contextual environment of the informer, information transmission and receiving media, and client. He states that the updated framework "acknowledged that they [the three components] exist within complex environments that greatly impact them," (Cohen 2009, p. 8).In our model, we use knowledge sharing (a form of informing) as our dependent variable. Our model examines the organizational practices that affect the complex environment in which the informing takes place.

The rest of the paper is organized as follows: first we discuss the theoretical background and previous research on national culture. Next, we discuss the theoretical basis for the knowledge-based view of the firm and formulate our hypotheses, proposing specific relationships between knowledge sharing and three key aspects of the knowledge-based view: business strategy, technology practices, and decision making. We then present the research methodology and data analysis results from two studies, one in the United States, the other in Japan. Finally, the conclusion is presented with a discussion of implications and the need for future research.

\section{Research Background}

\section{National Culture}

"National culture" can be defined as the profile of a society with respect to norms, values, and institutions (Hofstede, 2001). There are five dimensions that allow classification of countries: (1) individualism versus collectivism, (2) power distance, (3) uncertainty avoidance, (4) masculinity versus femininity, and (5) long-term versus short- term orientation (Hofstede, 2001). A country is positioned along these five dimensions to provide an overall summary of a country's cultural type (Hofstede, 2001). Research shows that national culture often influences business practices (Brett \& Okumura, 1998); however, there is a paucity of broad-based empirical research focusing on knowledge sharing in multiple national cultures. 
Table 1 shows studies that were conducted concerning knowledge sharing in differing national cultures or a cross-cultural environment, however, most of these studies do not incorporate the IT artifact or its immediate nomological net (Benbasat \& Zmud, 2003). While there were a few studies that addressed aspects of knowledge management in cross-cultural settings that were published in information systems journals, studies specifically concerning knowledge sharing in differing national cultures are missing. Only a handful of the knowledge sharing studies that were published in various journals use a broad-based data collection methodology. A number of the published studies use a case methodology, which provides rich contextual information, but lacks generalizability. In contrast, our study surveys a broad variety of organizations across multiple nations.

\begin{tabular}{|c|c|c|}
\hline \multicolumn{3}{|c|}{ Table 1: Cross-cultural studies on knowledge sharing } \\
\hline Authors & Findings & Context \\
\hline $\begin{array}{l}\text { Chow, Deng, \& } \\
\text { Ho (2000) }\end{array}$ & $\begin{array}{l}\text { There is an interactive effect between national culture and } \\
\text { contextual factors (nature of the knowledge and the } \\
\text { relationship between the parties involved) that leads to } \\
\text { employees' likelihood of sharing knowledge with co- } \\
\text { workers. }\end{array}$ & $\begin{array}{l}\text { Quantitative and open-ended responses to two } \\
\text { scenarios were collected from } 142 \text { managers } \\
\text { (104 from the U.S. and } 38 \text { from the People's } \\
\text { Republic of China). }\end{array}$ \\
\hline $\begin{array}{l}\text { Glisby \& Holden } \\
(2005)\end{array}$ & $\begin{array}{l}\text { A novel approach for doing business in Japan included being } \\
\text { in Japan, but not constantly, hiring resident or non-resident } \\
\text { Japanese, maintaining strong relationships, and having a } \\
\text { long-term vision but short-term focus, was found to be } \\
\text { successful. }\end{array}$ & $\begin{array}{l}\text { Case study, conducted at Rosendahl, a } 100 \\
\text { employee Danish firm, of their strategy to } \\
\text { compete in the Japanese market. }\end{array}$ \\
\hline $\begin{array}{l}\text { Griffith, Myers, \& } \\
\text { Harvey (2006) }\end{array}$ & $\begin{array}{l}\text { National culture influences relationship resources and the } \\
\text { linkage of relationship resources to knowledge resources. }\end{array}$ & $\begin{array}{l}1000 \text { surveys mailed and } 218 \text { were returned } \\
\text { completed (Japan }=113 ; \text { United States }=105) .\end{array}$ \\
\hline $\begin{array}{l}\text { Holden \& Von } \\
\text { Kortzfleisch } \\
(2004)\end{array}$ & $\begin{array}{l}\text { Knowledge transfer is analogous to translation in the } \\
\text { following ways: they both are 1) sense making activities, 2) } \\
\text { concerned with personal cognition and the interlingual } \\
\text { transfer of knowledge from head-to-head and into social } \\
\text { networks, and, 3) subject to constraints which affect } \\
\text { transferability (that is the extent to which knowledge can be } \\
\text { transmitted to others). }\end{array}$ & $\begin{array}{l}\text { Two models of knowledge transfer as } \\
\text { translation are proposed. }\end{array}$ \\
\hline $\begin{array}{l}\text { Vance \& Paik } \\
\text { (2005) }\end{array}$ & $\begin{array}{l}\text { Twelve categories of potentially beneficial forms of Host } \\
\text { Country National learning were identified and discussed } \\
\text { relative to their contributions to increased absorptive } \\
\text { capacity. These forms of learning included such areas as new } \\
\text { employee orientation and entry job skills, MNC predominant } \\
\text { language, MNC home country cross-cultural awareness, } \\
\text { supervision and technical operations management skills, } \\
\text { expatriate coaching and liaison skills, and MNC strategy and } \\
\text { culture. }\end{array}$ & $\begin{array}{l}\text { Open-ended exploratory field interviews with } 51 \\
\text { host country human resource and middle } \\
\text { managers in } 49 \text { different MNC foreign } \\
\text { subsidiaries with headquarters in six different } \\
\text { countries. }\end{array}$ \\
\hline $\begin{array}{l}\text { Zakaria, } \\
\text { Amelinckx, \& } \\
\text { Wilemon (2004) }\end{array}$ & $\begin{array}{l}\text { To build a winning virtual team, at the individual team } \\
\text { member level, self-management, communication, cultural } \\
\text { awareness and sensitivity, trust, and comfort with technology } \\
\text { are needed. At the group level, team goals, norms, problem } \\
\text { solving and conflict management, team learning, and the } \\
\text { balancing of relationships and tasks are needed. }\end{array}$ & $\begin{array}{l}\text { Proposed framework for the knowledge, skills, } \\
\text { and abilities needed at the individual and group } \\
\text { levels to build successful virtual teams. }\end{array}$ \\
\hline
\end{tabular}

The existing cross-cultural knowledge sharing studies have primarily focused upon differences in knowledge sharing based upon differences in elements of national culture. We use a different approach. Using the theoretical foundation of the knowledge-based view of the firm, we investigate common factors across multiple cultures that can facilitate successful knowledge sharing. To do so, we performed a broad-based survey of firms in two vastly differing national cultures - the western culture of the United States and the eastern culture of Japan. These two cultures were selected because they are highly developed societies that are opposite each other on the cultural 
scale and such extremes usually make excellent examples of cultural differences. In the section below we discuss how these two cultures differ.

\section{Eastern and Western National Cultures}

Although Hofstede's (2001) dimensions provide a way to classify a country's culture, it is important to note that countries share both similarities and differences across cultural dimensions (Newman \& Nollen, 1996). For example, Japan and the United States greatly vary on the individualism, uncertainty avoidance, power distance, and long-term orientation of Hofstede's dimensions. Furthermore, although both countries are classified as masculine, the United States is relatively less masculine (more feminine) than Japan because Japan has a score of 95 and the United States has a score of 62 on a scale of 100.

Japan is representative of a collectivist, large-power-distance, strong uncertainty-avoidance, masculine, and long-term-oriented culture. Social ties among organizational members impact feelings of harmonious interdependence (Hofstede, 2001; Triandis, 1995). Individuals will tend to avoid uncertainty in the long run through developing interdependence with other in-group members (Hofstede, 2001; Yamagishi, Cook, \& Watabe, 1998). The "Japanese often 'prefer' to belong to groups and place group interests above their own individual interests not because they intrinsically like to do so, but because it is in their own long-term interest" (Yamagishi et al., 1998, p. 167). The movement toward the collective is founded on the Japanese society's development of systems of mutual monitoring and sanctioning to curtail self-interested behavior (Yamagishi et al., 1998).

Alternatively, U.S. firms operate in an individualistic, small-power-distance, weak-uncertaintyavoidance and a more feminine and short-term-oriented cultural type. Given this cultural foundation, an individual is expected to minimize social interdependence in his interactions with others (Hofstede, 2001). Although individuals from this cultural type engage in relationships, they tend to restrain themselves from fully trusting their partners to minimize potential opportunistic behaviors of others, to whom they are not strongly tied by cultural norms or group goals. In summary, these two countries represent vastly different national cultures and provide an appropriate context for empirical assessment of comparison of organizational practices leading to knowledge sharing in two distinct national cultures.

\section{Knowledge Sharing and the Knowledge-Based View of the Firm}

The knowledge-based view of the firm focuses on knowledge as the most important strategic asset of the firm's resources. Organizational knowledge sharing is a key component of this view because researchers have found that knowledge sharing is the key to organizational productivity (Almeida \& Kogut, 1999; Hansen, 2002; Kostova, 1999). One phenomenon related to knowledge is that, unlike material assets that depreciate in value with use, knowledge assets appreciate in value with use: ideas breed new ideas, and shared knowledge stays with the giver while enriching the receiver (Davenport \& Prusak, 1998). Once knowledge is created there is an economy of scale that results from its sharing - both because more than one individual can use knowledge at the same time and because shared knowledge stimulates the creation of new knowledge. Hence, with an effective sharing process an organization can develop its knowledge base and enhance its competitiveness (Andrews \& Deiahaye, 2000; McEvily \& Chakravarthy, 2002).

Unlike studies focusing on individual characteristics, the knowledge-based view of the firm is fundamentally concerned with the nature of knowledge coordination within the firm (Grant, 1996). The degree to which IT managers are involved in strategic business planning and business managers are involved in IT strategic planning is influenced by an organizations' emphasis on knowledge management and the method by which decisions are coordinated in the organization 
(Kearns \& Sabherwal, 2006/07). We argue that these strategic, technological, and decision making organizational practices are important theoretical areas to investigate knowledge sharing within the organization. A discussion of each area and the development of our hypotheses (shown in Figure 1), including a rationale of why these practices are applicable in widely varying national cultures, follows.

It has become relatively accepted procedure to include a hypothesis for each path in a model rather than more generally state that we are testing the model as posited in Figure 1. One rationale for the inclusion of each path as a hypothesis, despite the likely inclusion of well known and more easily proved hypotheses, is that these hypotheses are not being tested separately, but rather within the context of the model. As a result the other relationships that are represented within the model could impact the known or more obvious relationships.

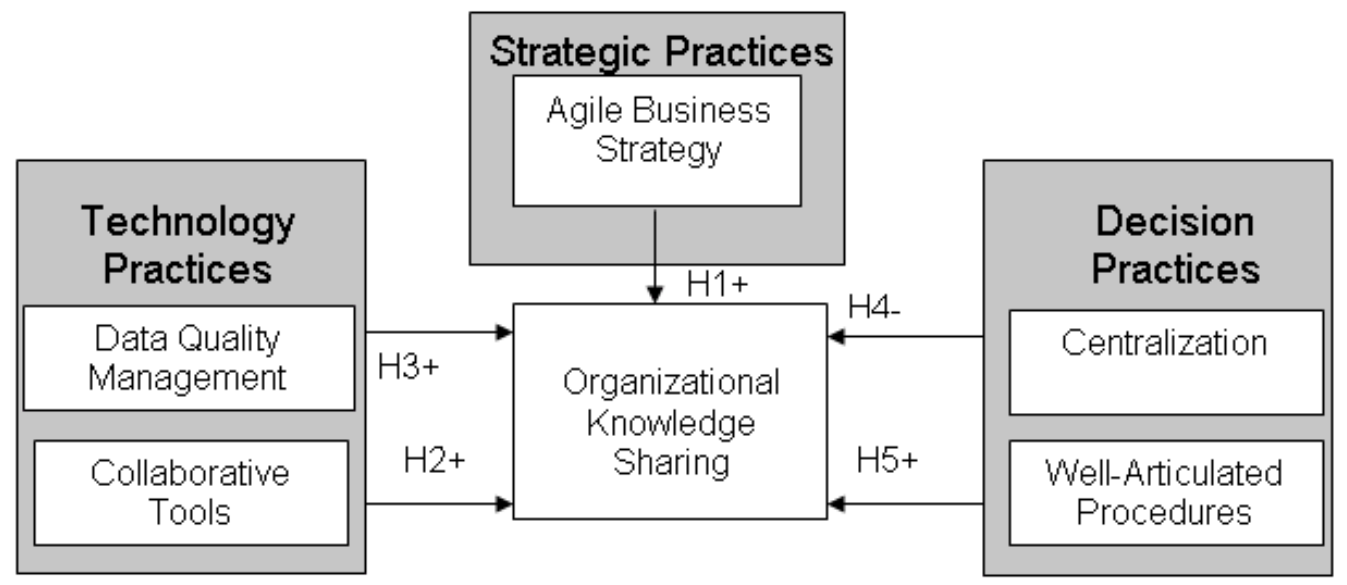

Figure 1: Hypothesized Research Model

\section{Strategic Practices}

Peter Drucker (1995) has written that "knowledge has become the key economic resource and the dominant - and perhaps, even the only - source of competitive advantage." Valuable knowledge often originates in individual experiences and perceptions (Polanyi, 1966), yet in order for firms to achieve a competitive advantage, knowledge must be coordinated at the organization level. Empirical studies have shown that knowledge management is a critical organizational capability through which IT influences firm performance. For example, in a study of 250 Fortune 1000 firms, a firm's KM capability produces and takes advantage of cross-unit synergies from the product, customer, and managerial knowledge resources of the firm (Tanriverdi, 2005). These knowledge resources, in turn, positively influence organizational performance. There is also evidence that business strategy affects knowledge flow within an organization (Vance \& Paik, 2005).

One specific type of business strategy found in the KBV literature is an agile business strategy. Organizational practices can lure firms into routines that are inconsistent with a changing environment. Practices for capturing, sharing, and using knowledge can become so inflexible that they lead to stagnation (Garud \& Kumaraswamy, 2005). Conversely, an agile business strategy is concerned with speed and flexibility as an organization interacts with its marketplace. In the section below, we posit that an agile business strategy is significantly related to knowledge sharing. 


\section{Agile Business Strategy}

An agile business strategy has four underlying principles (Goldman, Nagel, \& Preiss, 1995): 1) delivering value to the customer, 2) being ready for change, 3) valuing human knowledge and skills, and 4) forming virtual partnerships. Agile strategy making is used by firms operating in dynamic industries where strategic initiatives emerge in response to changing conditions. At its core, this agile business strategy utilizes fundamentals of strategic planning that incorporates organizational analytical thinking activities intended to consider various competitive and organizational insights and rationally determine how the overall organization is strategically positioned (Porter, 1996). In a rapidly changing business environment, an agile business strategy is often the strategy of choice because the classic bureaucratic model responds more slowly to swift transformations in the business environment.

Because valuing human knowledge and skills is a key principle in agility, organizations with this strategy place a high priority on managing and leveraging knowledge. Agility is closely aligned with an organization's ability to integrate and use knowledge (Hovorka \& Larsen, 2006). Acquiring strategic agility requires that an organization consistently identify, share, assimilate, and exploit new knowledge more effectively than the competition (Roth, 1996). Studies have shown that key capabilities for workforce agility are the collaboration of employees across functional boundaries and the ability of employees to effectively transfer knowledge (Breu, Hemingway, Strathern \& Bridger, 2002; Hovorka \& Larsen, 2006). Knowledge networks, that entail relationships among entities (individuals, teams, organizations) working on a common mission, are becoming increasingly popular because they embed the dynamism needed for collective and systematic knowledge asset creation and sharing.

It should be noted, however, that those with less agile business strategies might place an equivalent value on knowledge sharing as those with agile strategies. An example of this type of organization is IBM, which values employee knowledge sharing, as evidenced by programs such as rewarding employees for suggestions. Therefore, having an agile business strategy might not be significant in its correlation with knowledge sharing because of lack of variation among the respondents.

Despite cultural differences, agile business principles are embraced in multiple cultures. For example, Japanese firms are increasingly aware of the importance of agility in terms of their business strategy (Katayama \& Bennett, 1999). Also, research on 1,300 manufacturing business units across North America, Europe, and Japan called for agile strategies to leverage knowledge-based competencies such as combining "IT and state-of-the art manufacturing processes with technologically competent workers and intelligent organizations" (Roth, 1996, p. 33). Firms worldwide are realizing that an agile business strategy is critical to competing in the global marketplace in the short-term and to remaining viable as a competitive force in the long-term. These studies suggest that embracing an agile business strategy is a core practice that affects organizational knowledge sharing, even for organizations that operate in different national cultures. Thus, we propose that the same relationship holds in two considerably different national cultures:

H1a: There is a positive relationship between an agile business strategy and knowledge sharing in the United States.

H1b: There is a positive relationship between an agile business strategy and knowledge sharing in Japan.

\section{Technology Practices}

Information technology facilitates social interactions among various organizational levels. While technology alone is not a panacea for ensuring that knowledge will be shared, the knowledge- 
based view of the firm recognizes that IT is a powerful tool for enabling and coordinating the distribution of knowledge within and across organizational and geographical boundaries.

Social rules, which shape social processes and interaction behaviors, are built into technological infrastructures (DeSanctis \& Poole, 1994). The technological capability of sharing knowledge can alleviate problems regarding the distribution of knowledge that hierarchical social structure may at one time have reinforced. However, knowledge sharing, as the result of the presence of technological infrastructure, is not automatic. We argue that two types of technology practices (providing collaborative technology tools and ensuring that data quality management practices are in place) can help stimulate successful knowledge sharing.

\section{Collaborative Tools}

Collaborative tools allow individuals within the organization to work together and collaborate interactively. Collaboration is seen as one of the key ways in which knowledge is transmitted and created within the organization (Grant, 1996; O’Dell \& Grayson, 1998; Teece, 1998). It is important to identify relevant knowledge in various places of an organization to build a technical infrastructure that supports knowledge sharing and dissemination. Ideally, enabling technologies allow an organization to apply its collective intellect to a problem, regardless of time or geographic location. For example, knowledge sharing across subsidiaries in multiple countries required collaborative infrastructural systems (Zhao \& Luo, 2005). Using collaborative technologies, such as intranet-based repositories, can lead to faster access to information and reduced costs (Zakaria, Amelinck, \& Wilemon, 2004). Thus, the knowledge of individuals is converted into organizational knowledge through the process of knowledge sharing with the help of information technology (Nelson \& Cooprider, 1996).

The role of collaborative tools to support social construction of knowledge is evident in organizations around the world, despite differences in the individualistic versus collectivistic dimension of national culture. For example, using the Internet and collaborative technologies, the Electronic Community of Teachers (ECOT) was created across the Houston Independent School district in the United States to enable teachers to identify best practices, share experiences, and create relationships. Two years after its inception, almost 800 teachers were using the IT enabled infrastructure to share ideas and develop better curriculums (Brazelton \& Gorry, 2003). In Japan, a collectivist society, work was done on creating internet-based collaborative systems to support research and development in the field of industrial ecology. The goal was to allow researchers to associate fragments of knowledge generated at research centers from around the world (Kraines, Batres, Koyama, Wallace \& Komiyama, 2005). These web-based collaborative systems can address professional development needs through sharing knowledge and resources (Ford, 2006).

Therefore, past evidence suggests that effectively utilizing collaborative tools is a universal technology practice that fosters knowledge sharing. We caution, however, that just because a collaborative tool is installed, it does not necessarily mean that extensive knowledge sharing will result. Tools can be misused, under used, or used in organizational silos so that broad knowledge sharing will not occur. With these cautions in mind, we posit:

H2a: There is a positive relationship between using collaborative technological tools and knowledge sharing in the United States.

$H 2 b$ : There is a positive relationship between using collaborative technological tools and knowledge sharing in Japan. 


\section{Data Quality Management Practices}

In this paper we define data as recorded facts and figures (Kroenke, 2009). Data are essential building blocks in the creation of knowledge. Therefore the quality and integrity of data is critical for organizational members to feel comfortable with accessing and using data that they summarize and ultimately formulate into knowledge (Foss, Henderson, Johnson, Murray \& Stone, 2002). Data quality significantly influenced data warehousing usage and perceived impact (Hong, Katerattanakul, Hong, Cao, 2006). Assessments of data accuracy, relevancy, currency, understandability, and ability to locate were items that measured data quality. Unless intentional data management practices are in place, inaccuracies and inconsistencies can occur that go undetected and uncorrected and, as a result, the confidence that organizational members place in the data is diminished (Foss et al., 2002).

Well-established policies for creation, update, and access of data facilitate usage and sharing among knowledge workers. In many organizations, data are fragmented, inconsistent, or difficult to locate, therefore are not easily shared or used. Clearly defined data practices represent the foundational aspect of the knowledge management process because knowledge workers that trust the accuracy and timeliness of data are more likely to use, synthesize, and share it with others. For example, in a study of 132 health care professionals in UK, information quality was a significant predictor of effective knowledge sharing (Taylor \& Wright, 2004). In the automobile industry in Japan, the trend toward collaborative engineering over the web requires that product data models communicated among engineers are of high quality (Tanaka \& Kishinami, 2006). These studies in different national cultures imply that engaging in data management practices that support data quality is critical to facilitation of knowledge sharing, regardless of the particular national culture. Thus, in two vastly different national cultures, we hypothesize:

H3a: There is a positive relationship between data management practices that support data quality and knowledge sharing in the United States.

$H 3 b$ : There is a positive relationship between data management practices that support data quality and knowledge sharing in Japan.

\section{Decision Making Practices}

The knowledge-based view of the firm considers knowledge to be a principal resource that guides decision making. The allocation of decision making rights and the organizational structure by which decisions are made are fundamental concerns of the KBV (Conner \& Prahalad, 1996; Grant, 1996; Spender, 1996). In the area of decision making practices we note that organizational coordination policies alone are not sufficient to foster knowledge sharing among organizational members. We hypothesize that two decision making practices can help facilitate knowledge sharing.

\section{Well-Articulated Procedures}

Who interacts with whom and how they interact will have an impact on decision-making processes and the way that decisions are articulated to the rest of the organization (Hurst, Rush \& White, 1989). According to the KBV, the existence of a common language and shared meaning is a fundamental enabler to knowledge integration (Grant, 1996). Shared understanding facilitates coordinated activity. Therefore, communication effectiveness of the decisions made in organizations can affect employees' motivation levels and compliance.

Communication systems play an important role in interpersonal interaction. Existing communication structures, whether formal or informal, play a significant role in the dissemination of knowledge among organizational members (Thompson \& Fox, 2001); thus, well-articulated procedures 
are critical to effective knowledge transfer. Firms are able to capitalize on their analytical assets only if employees have a clear understanding of expectations. Unambiguous communication of decisions and the underlying rationale behind those decisions provides much needed coordination among individuals and groups of individuals with diverse specialized competence. Wellarticulated decision-making procedures that emphasize organizational goals and values are essential (Nonaka \& Takeuchi, 1995) for success.

Successful firms, regardless of geographical location or country affiliation, are able to articulate the link between their organizations' goals and objectives and what organizational members at all levels need to know, share, and learn to accomplish those goals. For example, knowledge about MNC operations and host country business goals promoted knowledge transfer between host country national executives and expatriates (Vance \& Paik, 2005). These past empirical results suggest that well articulated decision making procedures foster knowledge sharing regardless of the power distance index differentials in national culture.

We acknowledge there are examples that run counter to these arguments. For instance, an organization may have well defined policies, detailed in a written manual and accessible to all on the organization's website or intranet. However, knowledge sharing maybe be limited if the knowledge sharing flows only from top down and there is no feedback loop. Conversely, even when decision practices are not well articulated, there may be significant sharing occurring, even though that knowledge may be inaccurate or based on innuendo and rumors. For example, if an organization is expected to lay off workers, the decision making procedures regarding who will be laid off may not be communicated, but much sharing is done. Alavi and Leidner, (2001, p. 109) state that "Knowledge is information possessed in the mind of individuals: it is personalized information (which may or may not be new, unique, useful, or accurate)."

However, based on the preponderance of the former literature reviewed, we posit that in two countries with greatly differing national cultures:

H4a: There is a positive relationship between well articulated decision making procedures and knowledge sharing in the United States.

H4b: There is a positive relationship between well articulated decision making procedures and knowledge sharing in Japan.

\section{Centralization of Decisions}

According to the KBV, a centralized hierarchical arrangement for coordination is inadequate because knowledge that is tacit and sensitive is best communicated directly through individual specialists (Grant, 1997). According to Grant (1996, p. 118), "once firms are viewed as institutions for integrating knowledge, a major part of which is tacit and can only be exercised by those who possess it, then hierarchical coordination fails." Therefore, a hierarchical centralized structure inhibits inter-departmental communication and the frequency of idea sharing (Woodman, Sawyer \& Griffin, 1993). A centralized decision structure can also cause distortion, filtering, or reduction of content based on perceptions of what is desirable or, conversely, unacceptable to pass to higher levels of authority. Centralization is negatively associated with intra-corporate knowledge sharing (Tsai, 2002).

Flatter, decentralized decision structures give firms the flexibility needed to adapt to an everchanging environment (Sanchez \& Mahoney, 1996). Decentralization can facilitate timely knowledge sharing among organizational members because it facilitates the development of lateral network ties which, in turn, leads to enhanced knowledge transfer (Tsai, 2002). A modular organizational design can reduce the costs of coordination and adaptation, thereby increasing flexibility (Sanchez \& Mahoney, 1996). Decentralized decision structures also enable more spontaneous 
knowledge exchange and creation among employees (Hopper, 1990). Likewise, in South Korea, a relatively high power-distance country, knowledge creation via socialization was inversely related to centralized decision structures (Lee \& Choi, 2003). Decentralization enables members to establish lateral ties on their own initiative, without first seeking approval from headquarters. Consistent with this, we posit that in greatly differing national cultures:

H5a: There is a negative relationship between centralized decision making and knowledge sharing in the United States.

H5b: There is a negative relationship between centralized decision making and knowledge sharing in Japan.

\section{Research Method: United States}

\section{Instrument Development}

To create the survey, generally accepted instrument development guidelines were followed (Kerlinger \& Lee, 2000). In order to develop clear definitions of the constructs and their interrelationships, we reviewed relevant research streams. We borrowed questions from existing scales where possible. Further, to ensure that the survey items corresponded to the theoretical constructs, we received input from members of the Society of Information Managers (SIM) working group on Knowledge Management.

The Centralization of Decisions scale was taken from Miller and Friesen (1982). The WellArticulated Decision Making Practices and Agile Business Strategy scales were taken from Hoving (2003). Items for Organizational Knowledge Sharing, Data Quality Management Practices, and Collaborative Tool Usage scales were developed after an extensive literature review. The written survey instrument was refined through four iterations. First, several academicians with information systems survey research expertise reviewed the survey. Modifications were made based on the comments of these experts. Next, twelve executives from the SIM Knowledge Management (KM) Working Group reviewed the survey. Modifications were made based upon their comments. The SIM KM Working Group again reviewed the survey. Additional modifications were made based upon this round of comments. Fourth, a pilot study was conducted where 70 SIM respondents answered the survey electronically. Satisfied with the responses, content, and clarity of the survey, the final instrument was created. The items for each construct are shown in Table 2. 


\begin{tabular}{|c|c|c|c|c|c|}
\hline \multicolumn{6}{|c|}{ Table 2: Survey Items, Construct Reliabilities, and Factor Loadings } \\
\hline \multirow[b]{2}{*}{ Construct } & \multirow[b]{2}{*}{ Item } & \multicolumn{2}{|c|}{ United States } & \multicolumn{2}{|c|}{ Japan } \\
\hline & & ICR & Loading & ICR & Loading \\
\hline \multicolumn{6}{|l|}{$\begin{array}{c}\text { Organizational } \\
\text { Knowledge Sharing }\end{array}$} \\
\hline & People are ready and willing to share information at any time & & 0.86 & & 0.81 \\
\hline & $\begin{array}{l}\text { We effectively manage processes and share information } \\
\text { across all business functions }\end{array}$ & & 0.89 & & 0.86 \\
\hline & $\begin{array}{l}\text { Our company's incentives encourage the sharing of knowl- } \\
\text { edge and expertise in the organization }\end{array}$ & & & & \\
\hline \multicolumn{6}{|l|}{ Strategic Practices: } \\
\hline \multirow[t]{6}{*}{$\begin{array}{c}\text { Agile Business } \\
\text { Strategy }\end{array}$} & & 0.88 & & 0.89 & \\
\hline & $\begin{array}{l}\text { Our business is well positioned to compete in the changing } \\
\text { market space }\end{array}$ & & 0.82 & & 0.65 \\
\hline & $\begin{array}{l}\text { Our company 's business strategy is well understood by all } \\
\text { employees }\end{array}$ & & 0.74 & & 0.83 \\
\hline & $\begin{array}{l}\text { Our company achieves competitive advantage through our } \\
\text { information and knowledge management capabilities }\end{array}$ & & 0.71 & & 0.82 \\
\hline & $\begin{array}{l}\text { Our business has the short and long term strategy in place to } \\
\text { maintain market and customer share }\end{array}$ & & 0.81 & & 0.75 \\
\hline & $\begin{array}{l}\text { Our business structure is flexible and adequate to execute } \\
\text { organizational and regulatory changes }\end{array}$ & & 0.82 & & 0.84 \\
\hline \multicolumn{6}{|l|}{ Decision Practices: } \\
\hline \multirow[t]{4}{*}{ Well-Articulated Process } & & 0.88 & & 0.90 & \\
\hline & $\begin{array}{l}\text { Important decisions are made at this company considering } \\
\text { all relevant information }\end{array}$ & & 0.85 & & 0.79 \\
\hline & $\begin{array}{l}\text { Our company has a clearly defined decision process that is } \\
\text { understood by all managers and affected employees }\end{array}$ & & 0.86 & & 0.88 \\
\hline & $\begin{array}{l}\text { Our management makes timely decisions that are well com- } \\
\text { municated }\end{array}$ & & 0.86 & & 0.91 \\
\hline \multirow[t]{4}{*}{ Centralization } & & 0.91 & & 0.67 & \\
\hline & $\begin{array}{l}\text { To what extent is the responsibility to make the new product } \\
\text { introduction decisions in your company centralized at the top } \\
\text { level of management? }\end{array}$ & & 0.94 & & 0.90 \\
\hline & $\begin{array}{l}\text { To what extent is the responsibility to make the entry into } \\
\text { major new markets decisions in your company centralized at } \\
\text { the top level of management? }\end{array}$ & & 0.91 & & 0.71 \\
\hline & $\begin{array}{l}\text { To what extent is the responsibility to make the pricing of } \\
\text { major product line decisions in your company centralized at } \\
\text { the top level of management? }\end{array}$ & & 0.80 & & 0.22 \\
\hline \multicolumn{6}{|l|}{ Technology Practices: } \\
\hline \multicolumn{6}{|l|}{$\begin{array}{c}\text { Data Quality Manage- } \\
\text { ment }\end{array}$} \\
\hline & $\begin{array}{l}\text { We have a clearly defined source of record for all core busi- } \\
\text { ness data }\end{array}$ & & 0.80 & & 0.84 \\
\hline & $\begin{array}{l}\text { We have clearly identified business managers who are re- } \\
\text { sponsible for the integrity and timeliness of all company data }\end{array}$ & & 0.87 & & 0.87 \\
\hline & $\begin{array}{l}\text { We have clearly defined and well-followed policies for } \\
\text { information creation, update, access, and management }\end{array}$ & & 0.88 & & 0.88 \\
\hline \multirow[t]{5}{*}{ Collaborative Tools } & $\begin{array}{l}\text { To what extent are the following technologies used in } \\
\text { your organization? }\end{array}$ & 0.82 & & 0.85 & \\
\hline & Intranets & & 0.73 & & 0.64 \\
\hline & Extranets & & 0.70 & & 0.77 \\
\hline & Collaborative/Workgroup Technologies & & 0.79 & & 0.79 \\
\hline & Knowledge Repositories & & 0.82 & & 0.83 \\
\hline
\end{tabular}




\section{Data Collection}

In both US and Japan studies, our sample consisted of chief information officers (CIOs). The use of the senior IT executive as a "key informant" is a well-established approach used in empirical information systems studies (Segars \& Grover, 1998). In survey research like this, IT executives serving as key informants provide information on collective organizational properties and processes, rather than on personal characteristics (Venkatraman, 1989). With this approach, these informants are chosen because of their particular qualifications such as rank, experience, or expert knowledge.

In the United States, the questionnaire was mailed to 2,450 SIM members, with 142 undeliverable. The package included a cover letter and the survey. Three weeks after distribution, an electronic reminder was sent to the SIM membership. This yielded 268 responses, a $12 \%$ response rate. This is a slightly higher response rate than other published research that surveyed SIM executives (Ferratt, Agarwal, Brown, \& Moore, 2005). Non-response bias was assessed by the commonly used method of treating responses received after the deadline given (three weeks after the survey was mailed to the respondents) as being representative of non-respondents bias (Kerlinger \& Lee, 2000). T-tests on key constructs and demographic variables showed no significant differences between respondents and non-respondents. Responses were received from firms in 22 states. Firms employed a median of 4,000 employees. The industry breakdown for the responding firms is shown in Table 3.

\begin{tabular}{|l|r|r|r|r|}
\hline \multicolumn{5}{|c|}{ Table 3. Demographics by industry } \\
\hline & United States & \multicolumn{2}{|c|}{ Japan } \\
\hline Industry & $\#$ & $\%$ & $\#$ & $\%$ \\
\hline Banking and Finance & 7 & 2.5 & 9 & 5.9 \\
\hline Electronics & 27 & 9.8 & 14 & 9.2 \\
\hline Food and Beverage & 18 & 6.5 & 8 & 5.3 \\
\hline Health & 21 & 7.6 & 20 & 13.2 \\
\hline Consulting & 112 & 40.6 & 5 & 3.3 \\
\hline Industrial and Automotive & 34 & 12.3 & 39 & 25.7 \\
\hline Insurance & 10 & 3.6 & 2 & 1.3 \\
\hline Metals and Metal Products & 23 & 8.3 & 6 & 3.9 \\
\hline Petrochemical & 7 & 2.5 & 7 & 4.6 \\
\hline Process Industries & 6 & 2.2 & 13 & 8.6 \\
\hline Retail/Wholesale & 0 & 0.0 & 20 & 13.2 \\
\hline Telecommunications & 0 & 0.0 & 1 & .7 \\
\hline Transportation & 0 & 0.0 & 4 & 2.6 \\
\hline Other/Missing & 11 & 4.0 & 4 & 2.6 \\
\hline Total & 276 & 100.0 & 152 & 100 \\
\hline
\end{tabular}

\section{Reliability and Validity Assessment}

PLS was used to assess the internal consistency (reliability) and discriminant validity of the constructs in the context of the research model. The acceptable psychometric properties require that the following criteria are met: 1) internal consistencies exceed .70;2) loadings in a confirmatory factor analysis (CFA) exceed .70; 3) loadings are greater than cross-loadings; and 4) the square root of the average variance extracted (AVE) exceeds the inter-construct correlations (Chin, 1998a; Fornell \& Larcker, 1981). To assess reliability, composite reliabilities were calculated. Table 2 shows that these ranged from .87 to .91 and are above the recommended .70 level (Fornell \& Larcker, 1981). CFA results for the final items are presented in Table 4. All items exceed the .70 loading criterion. 


\begin{tabular}{|c|c|c|c|c|c|c|}
\hline \multicolumn{7}{|c|}{ Table 4: PLS confirmatory factor analysis } \\
\hline \multicolumn{7}{|c|}{ United States study } \\
\hline & KS & Dec_Proc & STR & Tech_Data & Dec_Centr & Tech_Tool \\
\hline STR1 & 0.4943 & 0.4504 & 0.8119 & 0.4165 & 0.1610 & 0.3807 \\
\hline STR2 & 0.4240 & 0.4931 & 0.7621 & 0.3962 & 0.1355 & 0.2414 \\
\hline STR3 & 0.4446 & 0.3684 & 0.7296 & 0.3967 & 0.0193 & 0.4179 \\
\hline STR4 & 0.3931 & 0.5084 & 0.7739 & 0.3624 & 0.1145 & 0.2770 \\
\hline STR5 & 0.4782 & 0.4820 & 0.7753 & 0.3618 & 0.1245 & 0.3556 \\
\hline Dec_Centr1 & -0.0176 & 0.0207 & 0.1468 & 0.0738 & 0.9021 & -0.1457 \\
\hline Dec_Centr2 & -0.0178 & 0.0353 & 0.1546 & 0.0697 & 0.8983 & -0.1316 \\
\hline Dec_Centr3 & -0.0161 & -0.0005 & 0.0726 & 0.0688 & 0.8214 & -0.0169 \\
\hline KS1 & 0.8182 & 0.5082 & 0.4341 & 0.3425 & -0.0091 & 0.2814 \\
\hline KS2 & 0.8543 & 0.5172 & 0.4890 & 0.5217 & -0.0068 & 0.4289 \\
\hline KS3 & 0.8299 & 0.5666 & 0.5283 & 0.5003 & -0.0307 & 0.4193 \\
\hline Dec_Proc1 & 0.5171 & 0.8313 & 0.4814 & 0.4465 & 0.0273 & 0.2408 \\
\hline Dec_Proc2 & 0.5495 & 0.8628 & 0.5147 & 0.4123 & 0.0500 & 0.2908 \\
\hline Dec_Proc3 & 0.5530 & 0.8466 & 0.5129 & 0.4571 & -0.0188 & 0.3821 \\
\hline Tech_Data1 & 0.4710 & 0.4585 & 0.4002 & 0.8157 & 0.1338 & 0.3577 \\
\hline Tech_Data2 & 0.4524 & 0.4446 & 0.4435 & 0.8655 & 0.0657 & 0.3510 \\
\hline Tech_Data3 & 0.4869 & 0.4132 & 0.4317 & 0.8578 & 0.0055 & 0.4672 \\
\hline Tech_Tool1 & 0.2287 & 0.2965 & 0.3476 & 0.3395 & -0.0503 & 0.6871 \\
\hline Tech_Tool2 & 0.1986 & 0.1863 & 0.2475 & 0.2317 & -0.0276 & 0.5971 \\
\hline Tech_Tool3 & 0.3878 & 0.2359 & 0.2582 & 0.3649 & -0.1591 & 0.7763 \\
\hline Tech_Tool4 & 0.4366 & 0.3281 & 0.4227 & 0.3966 & -0.0659 & 0.8399 \\
\hline \multicolumn{7}{|c|}{ Japan study } \\
\hline & KS & Dec_Proc & STR & Tech_Data & Dec_Centr & Tech_Tool \\
\hline STR1 & 0.2885 & 0.3611 & 0.6530 & 0.2766 & 0.2576 & 0.1642 \\
\hline STR2 & 0.5253 & 0.5701 & 0.8279 & 0.4075 & 0.1964 & 0.3503 \\
\hline STR3 & 0.5465 & 0.4936 & 0.8182 & 0.4843 & 0.1452 & 0.3606 \\
\hline STR4 & 0.3239 & 0.4284 & 0.7449 & 0.3866 & 0.1815 & 0.3403 \\
\hline STR5 & 0.5265 & 0.5940 & 0.8399 & 0.4758 & 0.1669 & 0.3139 \\
\hline Dec_Centr1 & 0.0666 & 0.2031 & 0.2700 & 0.1063 & 0.9003 & 0.0346 \\
\hline Dec_Centr2 & 0.0144 & 0.2020 & 0.2059 & 0.0042 & 0.7059 & 0.0026 \\
\hline Dec_Centr3 & -0.0320 & 0.1114 & 0.2015 & 0.0412 & 0.2228 & 0.0603 \\
\hline KS1 & 0.8075 & 0.4558 & 0.4964 & 0.4565 & 0.0879 & 0.3906 \\
\hline KS2 & 0.8608 & 0.4904 & 0.5354 & 0.5936 & 0.1096 & 0.4014 \\
\hline KS3 & 0.6942 & 0.5526 & 0.3613 & 0.3922 & 0.0057 & 0.2315 \\
\hline Dec_Proc1 & 0.4834 & 0.7939 & 0.5083 & 0.4001 & 0.2072 & 0.2304 \\
\hline Dec_Proc2 & 0.5577 & 0.8796 & 0.5634 & 0.4731 & 0.1460 & 0.3243 \\
\hline Dec_Proc3 & 0.5775 & 0.9101 & 0.5852 & 0.5339 & 0.1808 & 0.1940 \\
\hline Tech_Data1 & 0.4926 & 0.4653 & 0.4457 & 0.8392 & 0.0707 & 0.1908 \\
\hline Tech_Data2 & 0.5281 & 0.4560 & 0.4419 & 0.8723 & 0.0293 & 0.3201 \\
\hline Tech_Data3 & 0.5726 & 0.4971 & 0.4928 & 0.8836 & 0.1346 & 0.3811 \\
\hline Tech_Tool1 & 0.2067 & 0.1768 & 0.1910 & 0.1020 & 0.0779 & 0.6471 \\
\hline Tech_Tool2 & 0.2907 & 0.2225 & 0.3548 & 0.2385 & -0.0466 & 0.7710 \\
\hline Tech_Tool3 & 0.3315 & 0.2300 & 0.2456 & 0.2439 & 0.0446 & 0.7859 \\
\hline Tech_Tool4 & 0.4403 & 0.2433 & 0.3894 & 0.3914 & $\begin{array}{l}-0.0248 \\
\end{array}$ & 0.8337 \\
\hline
\end{tabular}


To assess discriminant validity, two criteria need to be met (Chin, 1988b). First, indicators should load more strongly on their corresponding construct than on other constructs in the model. Table 5 shows that loadings of items on their respective constructs were higher than cross-loadings of the items on other constructs. Second, the square root of the average variance extracted (AVE) (leading diagonal in Table 5) should be larger than the inter-construct correlations (implying that all constructs share more variance with their indicators than with other constructs). Since both criteria were met, we concluded that the constructs exhibit discriminant validity. These results suggest that the scales exhibit adequate psychometric properties.

Table 5: Correlations of latent variables

\begin{tabular}{|c|c|c|c|c|c|c|}
\hline \multicolumn{7}{|c|}{ United States Study } \\
\hline & KS & Dec_Proc & STR & Tech Data & Dec_Centr & Tech_Tool \\
\hline KS & 0.834 & & & & & \\
\hline Dec_Proc & 0.605 & 0.847 & & & & \\
\hline STR & 0.622 & 0.604 & 0.770 & & & \\
\hline Tech Data & 0.554 & 0.452 & 0.473 & 0.846 & & \\
\hline Dec Centr & 0.111 & -0.025 & 0.114 & 0.014 & 0.874 & \\
\hline Tech_Tool & 0.482 & 0.395 & 0.450 & 0.527 & -0.161 & 0.729 \\
\hline \multicolumn{7}{|c|}{ Japan Study } \\
\hline & KS & Dec_Proc & STR & Tech_Data & Dec_Centr & Tech_Tool \\
\hline KS & 0.790 & & & & & \\
\hline Dec_Proc & 0.627 & 0.863 & & & & \\
\hline STR & 0.593 & 0.641 & 0.780 & & & \\
\hline Tech_Data & 0.616 & 0.547 & 0.533 & 0.865 & & \\
\hline Dec_Centr & 0.090 & 0.204 & 0.230 & 0.092 & 0.673 & \\
\hline Tech Tool & 0.437 & 0.289 & 0.401 & 0.349 & 0.007 & 0.763 \\
\hline \multicolumn{7}{|c|}{$\begin{array}{l}\text { KS = Knowledge Sharing } \\
\text { Dec_Proc = Decision Practices: Well-Articulated Procedures } \\
\text { STR = Strategic Practices: Agile Business Strategy } \\
\text { Tech_Data = Technology Practices: Data Quality Management } \\
\text { Dec_Centr = Decision Practices: Centralization } \\
\text { Tech_Tool }=\text { Technology Practices: Collaborative Tools }\end{array}$} \\
\hline
\end{tabular}

\section{Structural Model Assessment}

Assessment of the structural model entails estimating the path coefficients and the $\mathrm{R}^{2}$ value. Path coefficients indicate the strengths of the relationships between the independent and dependent variables. The $\mathrm{R}^{2}$ value is a measure of the predictive power of a model for the dependent variable. PLS Graph, version 3, was used and all constructs were modeled as reflective. Bootstrap resampling method was used to determine the significance of the paths within the structural model. Table 6 shows the results from the United States study. The model explains 59 percent of the variation in knowledge sharing in United States study. The relationship between Knowledge Sharing and: 1) Agile Business Strategy supports hypothesis H1a and is statistically significant $(\mathrm{t}=3.72$, $\mathrm{p}<0.01)$; 2) Collaborative Tools used supports hypothesis H2a and is statistically significant ( $\mathrm{t}=$ $3.55, \mathrm{p}<0.01)$; 3) Data Quality Management Practices supports hypothesis H3a and is statistically significant $(\mathrm{t}=2.47, \mathrm{p}<0.01)$; 4$)$ Well Articulated Decision Procedures supports hypothesis $\mathrm{H} 4 \mathrm{a}$ and is statistically significant $(\mathrm{t}=5.72, \mathrm{p}<0.01)$. Centralization of Decisions was hypothesized to be negatively associated with Knowledge Sharing and while the path was negative, as posited, but it was not statistically significant and does not support $\mathrm{H} 5 \mathrm{a}(\mathrm{t}=1.17$; see Figure 2). 


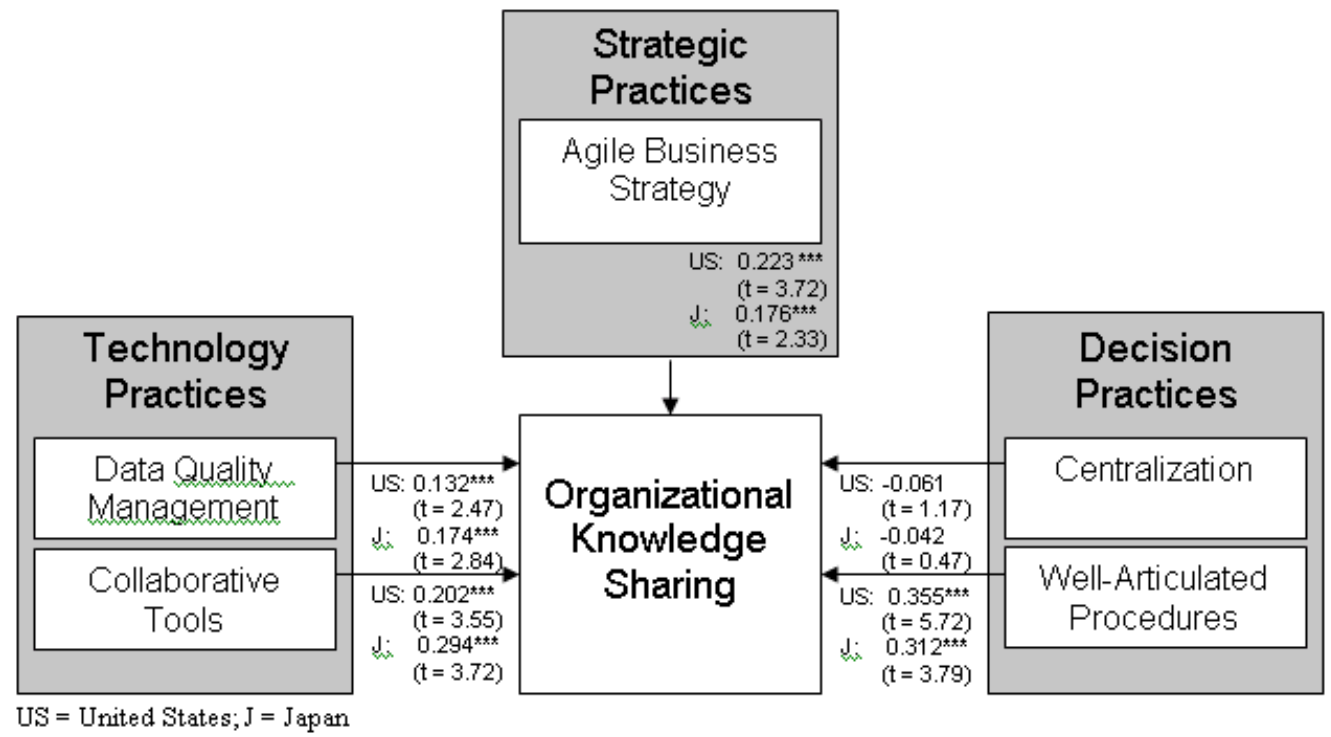

Figure 2: Path Diagram of the Hypothesized Model

\section{Research Method: Japan}

\section{Instrument Translation and Data Collection}

The instrument that was developed and tested in the United States was translated into Japanese by the Japan Institute of Chief Information Officers (JICIO). Bilingual native Japanese speakers reviewed the instrument and found it to be understandable and an accurate translation of the English-based instrument. Therefore, we were satisfied with the sufficiency of the translation.

In the Japan study, similar data collection procedures were used to that of the US. The questionnaire was mailed to 496 members of the Japan Institute of Chief Information Officers. The package included a comparable cover letter in Japanese to the one used with the US and the survey. This resulted in 152 responses; however, 9 were unusable, yielding a response rate of $28.8 \%$. In both samples, the responding firms represented a broad and varied sample (see Table 3 for industry classifications).

\section{Reliability and Validity Assessment}

The same process as described in the United States study was used to assess the internal consistency (reliability) and discriminant validity of the Japan study. To assess reliability, composite reliabilities were calculated. Table 2 shows that these were above the recommended .70 level (Fornell \& Larcker, 1981) except for Centralization (.67). CFA results for the final items are presented in Table 2. Most items exceed the .70 loading criterion with the exception of one item in the knowledge sharing, business strategy, centralization and tools used scales. Since these items did not cross-load and had acceptable loadings in the United States, it was decided to retain them in the analysis for comparative purposes.

Discriminant validity criteria were met (Chin, 1988b). First, indicators loaded more strongly on their corresponding construct than on other constructs in the model. Table 5 shows that loadings of items on their respective constructs were higher than cross-loadings of the items on other constructs. Second, the square root of the average variance extracted (AVE) (leading diagonal in Table 5) was larger than the inter-construct correlations (implying that all constructs share more va- 
riance with their indicators than with other constructs). These results support the contention that the scales exhibit adequate psychometric properties.

\section{Structural Model Assessment}

PLS was also used to test the model in Japan. The significance of the paths was determined using the t-statistic calculated with the bootstrapping technique. All constructs were modeled as reflective. Table 6 presents the results of the model fit in the Japan study. The model explains about $55 \%$ percent of the variation in knowledge sharing intention in the Japan Study. The relationship between Knowledge Sharing and: 1) Agile Business Strategy supports hypothesis H1b and is statistically significant $(\mathrm{t}=2.33, \mathrm{p}<0.01) ; 2)$ Collaborative Tools used supports hypothesis $\mathrm{H} 2 \mathrm{~b}$ and is statistically significant $(\mathrm{t}=3.72, \mathrm{p}<0.01) ; 3)$ Data Quality Management Practices supports hypothesis H3b and is statistically significant $(\mathrm{t}=2.84, \mathrm{p}<0.01) ; 4)$ Well Articulated Decision Procedures supports hypothesis $\mathrm{H} 4 \mathrm{~b}$ and is statistically significant $(\mathrm{t}=3.79, \mathrm{p}<0.01)$. Centralization of Decisions was hypothesized as negatively associated with Knowledge Sharing and while the path was negative, it was not statistically significant and does not support $\mathrm{H} 5 \mathrm{~b}(\mathrm{t}=0.47$; see Figure 2).

\section{Limitations}

This research provides strong evidence regarding the impact of organizational practices on knowledge sharing. However, as with all research, this investigation has limitations. First, the study suffers from potential response bias associated with the "single informant." However, this limitation must be weighted against the value of the information that these key informants can provide and the use of the senior IT executive as a "key informant" is a well-established approach used in empirical information systems studies (Gold, Malhotra, \& Segars, 2001). Structured methods of triangulation and multiple informants potentially yield the most accurate data regarding organizational properties. We encourage future research to use various triangulated data collection techniques gathered from multiples sources within organizations.

Next, while the United States and Japan vary widely on Hofstede's (2001) cultural scale, there are similarities between the two cultures. As discussed earlier, the two cultures are classified as "masculine" although Japan is classified as relatively more masculine. Testing the applicability of these results in a predominantly "feminine" national culture is warranted. In addition, the United States and Japan are both highly developed industrialized countries. Future research should examine the relevance of the model to developing countries.

\section{Post-Hoc Analysis}

Despite our investigation into the general applicability of certain practices we recognize that cultural differences still exist and potentially impact the strength of the relationships within our structural model. To examine these issues we conducted a post-hoc analysis that looked at differences within model relationships across cultures. To examine potential cultural differences in the strength and direction of the practices in our model related to knowledge sharing we compared the values of the standardized coefficients for each path in the model across the countries for statistically significant differences. Table 6 shows the coefficients for each path in the US and Japan, the $\mathrm{z}$ value for testing the significance of the difference in these pairs of coefficients (Paternoster, Brame, Mazerolle, Piquero, 1998) and the statistical significance ( $p$ value) of these differences. Despite the common use of other statistics, the correct statistic for this comparison of the coefficients in two different models is (Paternoster et al., 1998): 


$$
z=\frac{b_{1}-b_{2}}{\sqrt{S E_{b 1}^{2}+S E_{b 2}^{2}}} .
$$

Where $b_{1}$ is the coefficient in the US, $b_{2}$ is the coefficient in Japan, and $S E_{b 1}{ }^{2}$ and $S E_{b 2}{ }^{2}$ are their respective standard errors squared.

The $p$ values in Table 6 show that the country comparisons for all these path coefficients are different and statistically significant. In addition, this post-hoc analysis provides potential insights into precautions when fostering knowledge sharing within an organization because there are differences among the strength of the relationships with the practices and knowledge sharing. The results show that the strength of the coefficient is positive and greater in the US than Japan for Agile Business Strategy and Well-Articulated Decision Procedures. Conversely, the strength of the coefficient is positive and greater in Japan than in the US for Data Quality Management Practices and Collaborative Tools. Finally, Centralized Decisions was negatively related to knowledge sharing in both countries but was more negative in the US than in Japan.

\begin{tabular}{|c|c|c|c|c|c|c|c|c|c|}
\hline \multicolumn{10}{|c|}{ Table 6: Results } \\
\hline \multirow{2}{*}{$\begin{array}{l}\text { Dependent } \\
\text { Variable }\end{array}$} & \multirow{2}{*}{$\begin{array}{l}\text { Independent } \\
\text { Variables }\end{array}$} & \multicolumn{3}{|c|}{ United States } & \multicolumn{3}{|c|}{ Japan } & \multirow[b]{2}{*}{$\mathbf{Z}$} & \multirow[b]{2}{*}{$\mathbf{P}$} \\
\hline & & $\mathbf{R}^{2}$ & b & SE & $\mathbf{R}^{2}$ & b & SE & & \\
\hline \multirow[t]{6}{*}{ KS } & & 0.590 & & & 0.554 & & & & \\
\hline & STR & & 0.223 & 0.0599 & & 0.176 & 0.0755 & 6.3876 & 0.0000 \\
\hline & Dec_Proc & & 0.355 & 0.0620 & & 0.312 & 0.0823 & 5.4373 & 0.0000 \\
\hline & Dec_Centr & & -0.061 & 0.0520 & & -0.042 & 0.0896 & -2.3216 & 0.0102 \\
\hline & Tech_Data & & 0.202 & 0.0570 & & 0.294 & 0.0791 & -12.228 & 0.0000 \\
\hline & Tech_Tool & & 0.132 & 0.0534 & & 0.174 & 0.0612 & -6.869 & 0.0000 \\
\hline \multicolumn{10}{|c|}{$\begin{array}{l}\text { Dec_Proc }=\text { Decision Practices: Well-Articulated Procedures } \\
\text { STR = Strategic Practices: Agile Business Strategy } \\
\text { Tech_Data = Technology Practices: Data Quality Management } \\
\text { Dec_Centr = Decision Practices: Centralization } \\
\text { Tech Tool }=\text { Technology Practices: Collaborative Tools }\end{array}$} \\
\hline
\end{tabular}

We also performed a post-hoc analysis comparing knowledge sharing by industry using Analysis of Variance (ANOVA). In the US data there were significant differences $(p<.01)$, but in the Japan data there were not $(p>.05)$. Using the Bonferroni technique for pair-wise comparisons, we found knowledge sharing was significantly less in the Industrial and Automotive industry than in the Electronics $(p<.01)$, Food and Beverage $(p<.05)$ and Consulting $(p<.01)$ industries. Such a finding may be consistent with fact that the US Industrial and Automotive Industry has been transitioning to become more competitive but has yet to fully evolve. There were no other significant differences.

\section{Discussion}

Knowledge influences rules about strategy and competition because the foundation of industrialized economics has shifted from natural resources to intellectual assets. According to the knowledge-based theory of the firm (Grant, 1996), organizational level mechanisms are essential to facilitating knowledge sharing and usage. This research proposed and tested three categories of core organizational practices that encourage knowledge sharing: strategic, technology, and decision 
making. Our data empirically validate these core practices in firms across two distinct national cultures.

The first category of organizational practices, strategic practices, showed that an agile business strategy was significantly related to knowledge sharing. Information technology plays a key role in agile business strategies to allow rapid capture and sharing of knowledge in turbulent and fluctuating environments. Because organizations with an agile strategy frequently alter their business processes in responding to customers' needs (Lee, Kim, \& Park, 1999) it is imperative to share knowledge about what is done. Thus managing knowledge and change proficiency are interrelated competencies that are necessary for organizational agility.

Technology practices are the second category of practices related to knowledge sharing. The choice of collaborative technology tools used is the first practice in the technology category that is significantly related to knowledge sharing. Our data show that intranets, extranets, workgroup technologies, and knowledge repositories provide organizational members with the ability to work simultaneously, exchange ideas and expertise, and potentially access knowledge sources and best practices.

Data quality management practices are the second type of practices in the technology category that are significantly related to knowledge sharing. This study supports the need for structured approaches in data handling because the results show that well-established policies for creation, update, and access of data facilitate knowledge workers in accessing and sharing knowledge. Data that are inconsistent, out-of-date, or hard to find are not readily shared or used. When knowledge workers are able to rely on the accuracy and quality of data, they are more apt to synthesize and share it with others.

The third category of practices related to knowledge sharing, decision making, contained two practices: well-articulated decision procedures and centralization of decisions. Well-articulated decision procedures can inform employees regarding the relationship between their activities and organizational goals and objectives. By clearly understanding requirements and the rationale for such requirements, knowledge workers are more likely to act in a consistent manner and collaborate with others to ensure that the goals and objectives are accomplished.

In both the United States and Japan, centralization of decision making was negatively correlated with knowledge sharing as hypothesized, but in neither study was this association significant. The negative correlation is consistent with literature that suggests that when knowledge workers do not have decision-making authority, they are less likely to share their knowledge with others (Lee $\&$ Choi, 2003). However, other studies have found that concentrated or centralized decision making structures do not necessarily inhibit knowledge sharing, but consistency of decision making locus with other elements of the organizational culture to facilitate knowledge sharing is a requirement (Jones, Cline, \& Ryan, 2006). In Japan, although decision structures are often centralized, where senior managers talk with senior managers and junior employees talk with junior employees, information is frequently shared from junior-to-junior across levels of hierarchy in a back door fashion (Tan, Wei, Watson \& Walczuch, 1998). Therefore, what is espoused as centralized decision making may be a quasi-decentralized process.

In our post-hoc analysis we found that in the United States, firms in the industrial and automotive industry engaged in knowledge sharing significantly less than several other industries (electronics, food and beverage, and consulting). In Japan, there were no such differences between industries. Perhaps the remnant of the old US automotive culture still is an inhibiting factor. 


\section{Contribution and Implications for Research and Practice}

Gill and Bhattacherjee (2007) admonish researchers to perform research that informs both academicians as well as external clients. The findings from this study have a number of significant theoretical and managerial implications. For research, this study provides evidence that there are core practices fostering knowledge sharing that are relevant to both western and eastern national cultures. Many of the previous studies on knowledge sharing have been conducted in a single country, usually within the United States. By conducting studies in both the United States and Japan, this research produced an empirically tested model of common knowledge sharing practices that can be applied to countries with vastly different national cultures. Given the theoretically meaningful national cultural distinctions between Japan and the US and the importance of US-Japan business relationships, understanding of the common organizational practices that foster knowledge sharing activities is important.

Secondly, the finding that business strategy, technology, and decision making practices affect knowledge sharing within organizations is an important contribution. Overall, this work advances the existing literature by strengthening the theoretical foundation of the KBV of the firm (Grant, 1996), that conceptualizes the firm as an institution for integrating knowledge. Specific organizational coordinating mechanisms in the form of three categories of organizational practices, including business strategy, technology, and decision making were empirically shown to enhance knowledge sharing.

A third major contribution to research stems from the broad-based survey methodology in two counties by which this research was conducted. Many previous empirical cross-cultural studies used a case methodology, which provides the advantage of contextually rich data, but does so at the expense of generalizability.

Fourth, this research provides evidence that is specific to knowledge sharing rather than knowledge management, in general. It investigates this important area at the organizational level rather than the individual level. It does so by examining coordinating mechanisms, including technological practices, which is important, in particular, to the information systems discipline.

Fifth, our study contributes to the informing science transdiscipline. According to Cohen (2009), informing takes place in a complex environment. Our data show that informing in a firm is affected by the organizational practices adopted. Specifically, we identify strategic, technology and decision making practices that affect the complex environment in which knowledge sharing occurs. Our results reaffirm that the information transmission and receiving component in the Informing Science framework matters, since the choice of collaborative technology tools significantly influences the degree of knowledge sharing.

This study also has important implications for managers. As a result of our findings we suggest care in implementing and evaluating organizational management practices to avoid attributing all differentiation to differences in national culture. While many studies identify differences based upon national culture, this study identifies specific core practices that enhance knowledge sharing that are common across cultures. Our results support the claim that there are core practices that are widely applicable regardless of culture, and that differences in outcomes might be attributable to non-cultural characteristics.

Specifically, this study reinforces the notion that business strategy affects knowledge sharing within the organization. While embracing an agile business strategy is not necessarily appropriate for all organizations, knowledge sharing within the organization is more likely for firms that follow such an agile strategy. In today's global economy, in which many firms operate in multiple countries, the leveraging of employee knowledge through the intentional adoption of an agile business strategy can help enhance the firm competitiveness. 
Next, IT managers are responsible for setting up the technological infrastructure that allows sharing knowledge in the most effective manner. Ensuring that appropriate tools are available to support the creation and distribution of knowledge is important. Our research shows that intranets, extranets, workgroup, and knowledge repositories fall into this category. Organizations should carefully consider the acquisition of these tools. While this study does not attempt to quantify the benefits of enhanced knowledge sharing, managers can use improved knowledge sharing as an empirically supported but non-quantifiable benefit of such tools when considering their acquisition.

Third, good data management practices are critical for ensuring data quality and the resulting soundness of decisions. Our study further underscores the importance of such practices in terms of their relationship to knowledge sharing. Excellent data management practices create confidence that knowledge derived from data is well formulated and can be used to make reliable judgments.

Fourth, today's managers need to consider creating an atmosphere of transparency by clearly articulating decision procedures to their employees and making sure that they are consistently applied in various situations. Employees that understand how and why decisions are made are more likely to be receptive to them and support them as they discuss the decisions with others and as they carry out the ensuing decisions.

\section{Concluding Remarks}

This study addressed the following research question: "To what extent are core organizational practices that contribute to creating a knowledge sharing environment applicable in organizations that reside in distinctly different national cultures?" A paucity of prior research has investigated the role of national culture in key IT governance areas. In addition, much of the literature that exists involves conducting a study in a single country, usually the United States. As a result, there has been little understanding on how organizations from different national cultures perceive the relationships between organizational practices and knowledge sharing.

To investigate this research question, we used the KBV of the firm to frame the relationship between organizational practices and knowledge sharing. We proposed a model of three categories of organizational practices that affect knowledge sharing: business strategy, technology, and decision making. We then empirically tested this model in the United States and Japan; countries that represent nearly polar extremes in cultural values. While many empirical studies seek to identify differences based upon national culture, our objective was consistent with a goal of science; to seek universal knowledge in which general theories are not limited to specific societal or national contexts. A major contribution of this research is a generalizable KBV model of organizational practices in both western and eastern national cultures that is supported with empirical results from both the United States and Japan. Our model provides a baseline for exploring those practices that are beneficial in multiple cultures and is applicable for future research as well as current practice.

\section{References}

Alavi, M., \& Leidner, D. E. (2001). Review: Knowledge management and knowledge management systems: conceptual foundations and research issues. MIS Quarterly, 25(1), 107-136.

Alony, I., Whymark, G., \& Jones, M. (2007). Sharing tacit knowledge: A case study in the Australian film industry. Informing Science: the International Journal of an Emerging Transdiscipline, 10, 41-59. Retrieved from http://www.inform.nu/Articles/Vol10/ISJv10p041-059Alony360.pdf

Almeida, P., \& Kogut, B. (1999). Localization of knowledge and the mobility of engineers in regional networks. Management Science, 45, 905-917. 
Andrews, K. M., \& Deiahaye, B. L. (2000). Influences on knowledge processes in organizational learning: The psychosocial filter. Journal of Management Studies, 37(6), 797-810.

Benbasat, I., \& Zmud. R. W. (2003). The identity crisis within the IS discipline: Defining and communicating the discipline's core properties. MIS Quarterly, 27(2), 183-194.

Brazelton, J., \& Gorry, G. A. (2003). Creating a knowledge-sharing community: If you build it, will they come? Communications of the ACM, 46(2), 23-25.

Brett, J. M., \& Okumura, T. (1998). Inter- and intracultural negotiation: United States and Japanese negotiators. Academy of Management Journal, 41(5), 495-510.

Breu, K., Hemingway, C. J., Strathern, M., \& Bridger, D. (2002). Workforce agility: The new employee strategy for the knowledge economy. Journal of Information Technology, 17(1), 21-31.

Cheng, J. L.C. (1994). On the concept of universal knowledge in organizational science: Implications for cross-national research. Management Science, 40(1), 162-168.

Chin, W. (1998a). Issues and opinion on structural equation modeling. MIS Quarterly, 22(1), vii-xvi.

Chin, W. (1988b). The partial least squares approach for structural equation modeling. In G. A. Marcoulides (Ed.), Modern methods for business research, (pp. 295-336). Mahwah, NJ: Lawrence Erlbaum Associates.

Cho, K. R., \& Lee, J. (2004). Firm characteristics and MNC's intra-network knowledge sharing. Management International Review, 44(4), 435-455.

Chow, C. W., Deng, F. J., \& Ho, J. L. (2003). The openness of knowledge sharing within organizations: A comparative study of the United States and the People's Republic of China. Journal of Management Accounting Research, 12, 65-95.

Cohen, E. B. (1999). From ugly duckling to swan: Reconceptualizing information systems as a field of the discipline informing science. Journal of Computing and Information Technology, 7(3), 213-219.

Cohen, E. B. (2009). A philosophy of informing science. Informing Science: the International Journal of an Emerging Transdiscipline, 12, 1-15. Retrieved from http://www.inform.nu/Articles/Vol12/ISJv12p001-015Cohen399.pdf

Conner, K. R., \& Prahalad, C. K. (1996). A resource-based theory of the firm: Knowledge versus opportunism. Organization Science, 7(5), 477-501.

Davenport, T. H., \& Prusak, L. (1998). Working knowledge: How organizations manage what they know. Cambridge, MA: Harvard Business School Press.

DeSanctis, G., \& Poole, M. S. (1994). Capturing the complexity in advanced technology use: Adaptive structuration theory. Organization Science, 5(2), 121-147.

Drucker, P. F. (1995). The information executives truly need. InformationWeek, 525, 89-93.

Ferratt, T. W., Agarwal, R., Brown, C. V., \& Moore, J. (2005). IT human resource management configurations and IT turnover: Theoretical synthesis and empirical analysis. Information Systems Research, $16(3), 237-257$.

Ford, N. J. (2006). The development and evaluation of an information technology support system to facilitate inter-organizational collaboration in HRD. Journal of European Industrial Training, 30(7), 569588.

Fornell, C., \& Larcker, D. F. (1981). Evaluating structural equation models with unobservable variables and measurement error. Journal of Marketing Research, 18(1) 39-50.

Foss, B., Henderson, I., Johnson, P., Murray, D., \& Stone, M. (2002). Managing the quality and completeness of customer data. Journal of Database Management, 10(2), 139-158.

Gackowski, Z. J. (2004). What to teach business students in MIS courses about data and information. Issues in Informing Science \& Information Technology, 1, 845-867. 
Gill, G., \& Bhattacherjee, A. (2007). The Informing Sciences at a Crossroads: The Role of the Client. Informing Science: the International Journal of an Emerging Transdiscipline, 10, 17-39. Retrieved from http://www.inform.nu/Articles/Vol10/ISJv10p017-039Gill317.pdf

Garud, R., \& Kumaraswamy, A. (2005). Vicious and virtuous circles in the management of knowledge: the case of Infosys technologies. MIS Quarterly, 29(1), 9-33.

Glisby, M. \& Holden, N. (2005). Applying knowledge management concepts to the supply chain: How a Danish firm achieved a remarkable breakthrough. Japan Academy of Management Executive, 19(2), 85-89.

Gold, A. H., Malhotra, A., \& Segars, A. H. (2001). Knowledge management: An organizational capabilities perspective. Journal of Management Information Systems, 18(1), 185-114.

Goldman, S., Nagel, R., \& Preiss, K. (1995). Agile competitors and virtual organizations. New York: Van Nostrand Reinhold.

Grant, R. M. (1996). Toward a knowledge-based theory of the firm. Strategic Management Journal, 17, 109-122.

Grant, R. M. (1997). The knowledge-based view of the firm: Implications for management practice. Long Range Planning, 30(3), 450-454.

Griffith, D. A, Myers, M. B., \& Harvey, M. G. (2006). An investigation of national culture's influence on relationship and knowledge resources in interorganizational relationships between Japan and the United States. Journal of International Marketing, 14(3), 1-32.

Hansen, M. T. (2002). Knowledge networks: Explaining effective knowledge sharing in multiunit companies. Organization Science, 13, 232-248.

Hofstede, G. (2001). Culture's consequences. Thousand Oaks, CA: Sage Publications.

Holden, N. J., \& Von Kortzfleisch, H. F. O. (2004). Why cross-cultural knowledge transfer is a form of translation in more ways than you think. Knowledge \& Process Management, 11(2), 127-136

Hong, S., Katerattanakul, P., Hong, S., \& Cao, Q. (2006). Usage and perceived impact of data warehouses: A study in Korean financial companies. International Journal of Information Technology and Decision Making, 5(2), 297-315.

Hopper, M. D. (1990). Rattling SABRE - new ways to compete on information. Harvard Business Review, $68(3), 118-125$.

Hovorka, D. S., \& Larsen, K. R. (2006). European enabling agile adoption practices through network organizations. Journal of Information Systems, 15(2), 159-168.

Hoving, R. (2003). Knowledge management: Coming up the learning curve. In C. V. Brown and H. Toppi (Eds.), IS management handbook (pp. 843-857). Boca Raton, FL: CRC Press,

Hurst, D. K., Rush, J. C., \& White, R. E. (1989). Top management teams and organizational renewal. Strategic Management Journal, 87-105.

Jones, M. C., Cline, M., \& Ryan, S. (2006). Exploring knowledge sharing in ERP implementation: An organizational culture framework. Decision Support Systems, 41(2), 411-434.

Katayama, H., \& Bennett, D. (1999). Agility, adaptability and leanness: A comparison of concepts and a study of practice. International Journal of Production Economics, 60/61(3), 43-51.

Kearns, G. S., \& Sabherwal, R. (2006/2007). Strategic alignment between business and information technology: A knowledge-based view of behaviors, outcome, and consequences. Journal of Management Information Systems, 23(3), 129-162.

Kerlinger, F. N., \& Lee, H. B. (2000). Foundations of behavioral research (4th ed.). Fort Worth: Harcourt Brace. 
Kettinger, W. J., Lee, C. C., \& Lee, S. (1995). Global measures of information service quality: A crossnational study. Decision Sciences, 26(5), 569-588.

Kostova, T. (1999). Transnational transfer of strategic organizational practices: A contextual perspective. Academy of Management Review, 24, 306-324.

Kraines, S., Batres, R., Koyama, M., Wallace, D., \& Komiyama, H. (2005). Internet-based integrated environmental assessment: Using ontologies to share computational models. Journal of Industrial Ecology, $9(3), 31-50$.

Kroenke, D. M. (2009). Using MIS. Upper Saddle River, New Jersey: Prentice Hall.

Lee, H., \& Choi, B. (2003). Knowledge management enablers, processes, and organizational performance: An integrative view and empirical examination. Journal of Management Information Systems, 20(1), $179-228$.

Lee, H. B., Kim, J. W., \& Park, S. J. (1999). KWM: Knowledge-based workflow model for agile organization. Journal of Intelligent Information Systems, 13(3), 261-287.

Leidner, D. E., \& Kayworth, T. (2006). Review: A review of culture in information systems research: Toward a theory of information technology culture conflict. MIS Quarterly, 30(2), 357-399.

Malhotra, A., Gosain, S., \& Sawy, O. A. (2005). Absorptive capacity configurations in supply chains: Gearing for partner-enabled market knowledge creation. MIS Quarterly, 29(1), 145-187.

Marchese, M. C. (2001). Matching management practices to national culture in India, Mexico, Poland, and the U.S. The Academy of Management Executive, 15(2), 130-132.

McEvily, S. K., \& Chakravarthy, B. (2002). The persistence of knowledge-based advantage: An empirical test for product performance and technological knowledge. Strategic Management Journal, 285-305.

Miller, D., \& Friesen, P. H. (1982). Innovation in conservative and entrepreneurial firms: Two models of strategic momentum. Strategic Management Journal, 3(1), 1-25.

Nelson, K. M., \& Cooprider, J. G. (1996). The contribution of shared knowledge to IS group performance. MIS Quarterly, 20(4), 409-429.

Newman, K. L., \& Nollen, S. D. (1996) Culture and congruence: The fit between management practices and national culture. Journal of International Business Studies, 27(4), 753-779.

Nonaka, I., \& Takeuchi, H. (1995). The knowledge creating company: How Japanese companies create the dynamics of innovation. New York: Oxford University Press.

O'Dell, C., \& Grayson, C. (1998). If only we knew what we know: Identification and transfer of internal best practices. California Management Review, 40(3), 154-174.

Paternoster, R., Brame, R., Mazerolle, P., \& Piquero, A. (1998). Using the correct statistical test for the equality of regression coefficients. Criminology, 36(4), 859-866.

Polanyi, M. (1966). The tacit dimension. New York, NY: Anchor Day Books.

Porter, M. E. (1996). What is strategy? Harvard Business Review, 61-78.

Roth, A.V. (1996). Achieving strategic agility through economies of knowledge. Strategy \& Leadership, 24(2), 30-36

Sanchez, R., \& Mahoney, J. T. (1996). Modularity, flexibility and knowledge management in product and organization design. Strategic Management Journal, 17, 63-76.

Segars, A. H., \& Grover, V. (1998). Strategic information systems planning success: An investigation of the construct and its measurement. MIS Quarterly, 22(2), 139-163.

Spender, J. C. (1996). Making knowledge the basis of a dynamic theory of the firm. Strategic Management Journal, 17, 45-63. 
Tan, B. C. Y., Wei, K., Watson, R. T., \& Walczuch, R. M. (1998). Reducing status effects with computermediated communication: Evidence from two distinct national cultures. Journal of Management Information Systems, 15(1), 119-141.

Tanaka, F., \& Kishinami, T. (2006). STEP-based quality diagnosis of shape data of product models for collaborative E-engineering. Computers in Industry, 57(3), 245-260.

Tanriverdi, H. (2005). Information technology relatedness, knowledge management capability, and performance of multibusiness firms. MIS Quarterly, 29(2), 311-334.

Taylor, W. A., \& Wright, G. H. (2004). Organizational readiness for successful knowledge sharing: Challenges for public sector managers. Information Resources Management Journal, 17(2), 22-37.

Teece, D. (1998). Research directions for knowledge management. California Management Review, 40(3), 289-292.

Thompson, L., \& Fox, C. R. (2001). Negotiation within and between groups in organizations: Levels of analyses. In M. E. Turner (Ed.), Groups at work: Theory and Research. Mahwah, NJ: Lawrence Erlbaum Associates.

Triandis, H. C. (1995). Individualism and collectivism. Boulder, CO: Westview Press.

Tsai, W. (2002). Social structure of 'competition' within a multiunit organization: Coordination, competition, and intra-organizational knowledge sharing. Organization Science, 13(2), 179-192.

Tsoukas, H., \& Vladimirou, E. (2001). What is organizational knowledge? Journal of Management Studies, 38(7), 973-993.

Tuomi, I. (1999/2000). Data is more than knowledge: Implications of the reversed knowledge hierarchy for knowledge management and organizational memory. Journal of Management Information Systems, 16(3), 103-117.

Vance, C. M., \& Paik, Y. (2005). Forms of host-country national learning for enhanced MNC absorptive capacity. Journal of Managerial Psychology, 20(7), 590-606.

Venkatraman, S. (1989). Endogenous diffusion of technology. International Journal of Industrial Organization, 7(4), 471-487.

Woodman, R.W, Sawyer, J. E., \& Griffin, R. W. (1993). Toward a theory of organizational creativity. The Academy of Management Review, 18(2), 293-321.

Yamagishi, T., Cook, K. S., \& Watabe, W. (1998). Uncertainty, trust and commitment formation in the United States and Japan. American Journal of Sociology, 104(1), 165-94.

Zakaria, N., Amelinckx, A., \& Wilemon, D. (2004). Working together apart? Building a knowledgesharing culture for global virtual teams. Creativity \& Innovation Management 13(1), 15-29.

Zhao, H., \& Luo, Y. (2005). Antecedents of knowledge sharing with peer subsidiaries in other countries: A perspective from subsidiary managers in a foreign emerging market. Management International Review, 45(1), 71-97. 


\section{Biographies}
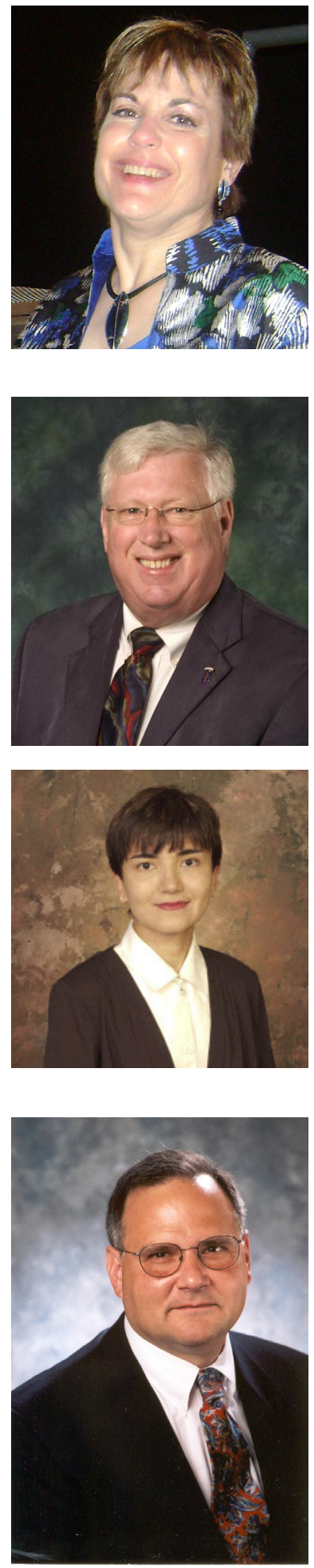

Sherry D. Ryan is an Associate Professor of Information Technology and Decision Sciences at the University of North Texas. She received her Ph.D. in IS from the University of Texas at Arlington and an MBA from the University of Southern California. Prior to returning to academia she worked for IBM, teaching courses and speaking at national conferences. Her research interests include knowledge management, IT human resource issues, and virtual teams and communities. Her work has appeared in journals including Journal of Management Information Systems, Decision Support Systems, Information and Management, and DATA BASE.

John C. Windsor is a professor of Information Systems and former Director of the Information Systems Research Center at the University of North Texas. He received his Ph.D. in Decision Sciences from Georgia State University. He has published over six books and 60 articles in such journals as Data Base, IIE Transactions, Information \& Management and Computers \& Security. His research interests include software and data engineering, systems security, collaborative computing, and the organizational impact of information technology.

Bashorat Ibragimova received her $\mathrm{PhD}$ in MIS from the University of North Texas and an MBA in International Management from Baylor University. Her research interests include cross-cultural studies of IT, knowledge management, IT security, organizational factors and egovernment issues. Her work has appeared in the Business Process Management Journal, Proceedings of the International Conference on Information Systems, Proceedings of Decision Science Institute and Proceedings of the Americas Conference on Information Systems.

Victor R. Prybutok is a Regents Professor of Decision Sciences in the Information Technology and Decision Sciences Department and Coordinator of the ITDS Department Doctoral Program in the College of Business at the University of North Texas. He received, from Drexel University, his B.S. with High Honors in 1974, a M.S. in BioMathematics in 1976, a M.S. in Environmental Health in 1980, and a Ph.D. in Environmental Analysis and Applied Statistics in 1984. Dr. Prybutok is an ASQ certified quality engineer, certified quality auditor, certified manager of quality / organizational excellence, and served as a Texas Quality Award Examiner in 1993. Dr. Prybutok has authored over 100 journal articles, several book chapters, and more than 70 conference presentations in information systems measurement, quality control, risk assessment, and applied statistics. 